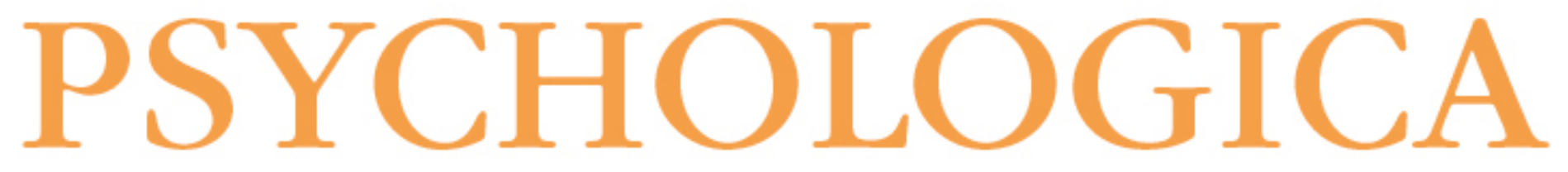

Exposição à violência familiar e abuso íntimo em jovens: que relação?

Autor(es): $\quad$ Faias, Joana; Caridade, Sónia; Cardoso, Jorge

Publicado por: Imprensa da Universidade de Coimbra

URL

persistente: URI:http://hdl.handle.net/10316.2/40754

DOI: $\quad$ DOI:https://doi.org/10.14195/1647-8606_59-1_1

Accessed : $\quad$ 26-Apr-2023 11:32:18

A navegação consulta e descarregamento dos títulos inseridos nas Bibliotecas Digitais UC Digitalis, UC Pombalina e UC Impactum, pressupõem a aceitação plena e sem reservas dos Termos e Condições de Uso destas Bibliotecas Digitais, disponíveis em https://digitalis.uc.pt/pt-pt/termos.

Conforme exposto nos referidos Termos e Condições de Uso, o descarregamento de títulos de acesso restrito requer uma licença válida de autorização devendo o utilizador aceder ao(s) documento(s) a partir de um endereço de IP da instituição detentora da supramencionada licença.

Ao utilizador é apenas permitido o descarregamento para uso pessoal, pelo que o emprego do(s) título(s) descarregado(s) para outro fim, designadamente comercial, carece de autorização do respetivo autor ou editor da obra.

Na medida em que todas as obras da UC Digitalis se encontram protegidas pelo Código do Direito de Autor e Direitos Conexos e demais legislação aplicável, toda a cópia, parcial ou total, deste documento, nos casos em que é legalmente admitida, deverá conter ou fazer-se acompanhar por este aviso. 
VOLUME 5

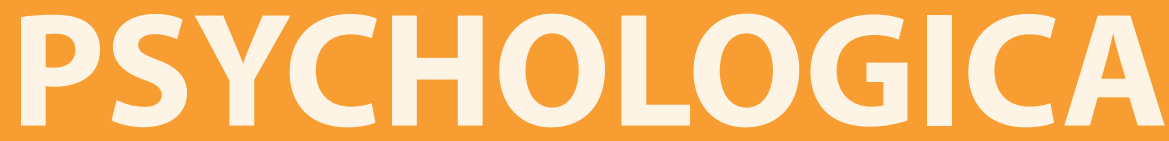

IMPRENSA DA UNIVERSIDADE DE COIMBRA

COIMBRA UNIVERSITY PRESS

FACULDADE DE PSICOLOGIA E DE CIÊNCIAS

DA EDUCAÇÃO DA UNIVERSIDADE DE COIMBRA 


\title{
Exposição à violência familiar e abuso íntimo em jovens: Que relação?
}

\author{
Joana Faias ${ }^{1}$, Sónia Caridade ${ }^{2}$ e Jorge Cardoso ${ }^{3}$
}

Exposure to family violence and dating violence: What relationship?

\begin{abstract}
This study analyses the relationship between exposure to family violence and dating violence. We used the Children's Natural Family Environment Signalling Scale and the Revised Conflict Tactics Scale. Five hundred and five young people average aged 21.76 $(S D=2.15)$ participated in the study. The results revealed high rates of prevalence of dating violence, being psychological aggression the most frequent typology, in the perpetration and victimization $(52.3 \%-50.4 \%$, respectively). There is evidence of high rates of violence $(80.8 \%)$ in family context, emotional violence is highlighted $(74.3 \%)$, followed by control (65.9\%), coercion (34.5\%) and, lastly, physical violence (16.4\%). The association analyses have proved that there is a positive relationship between dating violence and exposure to family violence. We reiterate the need for the creation of measures of prevention and intervention in family violence, given its potential impact on intimate relational dynamics.
\end{abstract}

Keywords: intimate relationships; dating violence; family violence; exposure

\footnotetext{
Faculdade de Ciências Humanas e Sociais, Universidade Fernando Pessoa. Email: joanacfaias@gmail.com

2 Faculdade de Ciências Humanas e Sociais, Universidade Fernando Pessoa. Email: soniac@ufp.edu.pt

3 Instituto Superior de Ciências da Saúde Egas Moniz. Email: jorgecardoso.psi@gmail.com
} 


\section{Resumo}

Este estudo analisa a relação entre a exposição à violência familiar e o abuso íntimo juvenil. Para tal recorreu-se à Escala de Sinalização do Ambiente Familiar Natural Infantil e

à Escala de Táticas de Conflitos Revisada. Participaram no estudo 505 jovens com uma média de idades de $21.76(D P=2.15)$. Os resultados revelaram altas taxas de prevalência do abuso íntimo, sendo a agressão psicológica a tipologia mais frequente, na perpetração e vitimação (52.3\% - 50.4\%, respetivamente). Apuraram-se elevadas taxas de violência ( $80.8 \%)$ no contexto familiar, destacando-se a violência emocional (74.3\%), seguida do controlo (65.9\%), a coerção (34.5\%) e por fim, a violência física (16.4\%). As análises de associação comprovaram que existe uma relação positiva entre o abuso íntimo e a exposição à violência familiar. Reitera-se, assim, a necessidade de criação de medidas de prevenção e intervenção na violência familiar, atendendo ao seu potencial impacto nas dinâmicas íntimas relacionais.

Palavras-chave: relações amorosas; abuso íntimo; violência familiar; exposição

\section{INTRODUÇÃO}

As relações amorosas constituem um marco importante no desenvolvimento pessoal de qualquer adolescente ou jovem, na medida em que proporcionam oportunidades para a exploração pessoal, a satisfação de necessidades (como o companheirismo, a intimidade e a autonomia), fomentando ainda a aprendizagem de papéis práticos e sociais necessários para a idade adulta e também para futuros relacionamentos amorosos (Ehlert, 2007; Furman \& Wehner, 1997). Não obstante, constitui, não raras vezes, um período particularmente propício à formação de certas crenças e atitudes sobre os relacionamentos e o abuso de poder, os quais irão também servir de base para o desenvolvimento de certas competências e modelos de comportamentos (Wolfe \& Feiring, citados em Ehlert, 2007).

Face à comprovada importância que o estabelecimento de vínculos amorosos pode desempenhar no desenvolvimento do jovem, importa igualmente estudar as dinâmicas abusivas e perceber de que forma estas emergem e se desenvolvem, perpetuando-se ao longo da vida do jovem.

Diversas têm sido as investigações (e.g., Cuevas, Sabina, \& Bell, 2014; FernandézGonzález, O’Leary, \& Muñoz-Rivas, 2014; Ferreira, 2011; Machado, Caridade, \& Martins, 2010) que comprovam que as experiências de abuso íntimo, nas suas mais diversas tipologias, constituem uma realidade muito frequente nas relações amorosas de muitos jovens. Neste sentido, cita-se aquele que constitui um dos maiores 
estudos internacionais desenvolvidos neste domínio - International Dating Violence Study - conduzido por Straus (2004), o qual envolveu 31 universidades de 16 países, comprovando que os indicadores de violência física nas relações amorosas juvenis se poderão situar entre os $17 \%$ e os $45 \%$, nos últimos 12 meses.

A maioria dos estudos em matéria de abuso íntimo tem demonstrado que a violência psicológica assume alguma preponderância comparativamente com outras formas de abuso investigadas. Mais concretamente, um estudo conduzido recentemente por Fernandéz-González e colaboradores (2014) encontrou taxas elevadas de violência íntima, concluindo que a violência psicológica constitui a tipologia abusiva mais preponderante (90\%), seguida da violência física (40\%) e por fim, o abuso sexual (reportado por $27.1 \%$ do sexo masculino e por $10.9 \%$ do sexo feminino). Num outro trabalho recente (Castañeda, Grande, Díez-Gañán, Sonego, \& Gavín, 2014), no qual participaram 3377 sujeitos, com idades compreendidas entre os 15 e 16 anos, as raparigas admitiram com maior frequência ter sofrido violência sexual (5.3\% vs. $2.4 \%)$ e também violência física e/ou sexual (7.1\% vs. 5.1\%). Já os rapazes reportaram sofrer preponderantemente violência física (4.0\% vs. 2.9\%).

Também no contexto português, a investigação nesta área tem vindo a expandir-se, procurando-se a caracterização da extensão e das dinâmicas que este problema assume no nosso país (cf. Caridade, 2011). Tal como acontece no contexto internacional, as taxas de prevalência do abuso íntimo no nosso país são variáveis, oscilando entre os 14\% (Mendes, 2006) e os 55\% (Oliveira \& Sani, 2005). A título exemplificativo, um estudo recente (Barros, 2014), tendo por base uma amostra de 262 participantes, apurou que a tipologia de violência mais frequente era o abuso psicológico, quer em termos de perpetração e de vitimação (51.1.\% vs. $45.4 \%$, respetivamente), seguindo-se a coerção sexual (22.5\% vs. 24.4.\%), o abuso físico sem sequelas (17.9\% vs. 16\%), e por fim, com percentagens menos expressivas, mas não negligenciáveis, surgiu o abuso físico com sequelas (3.4\% vs. 3.4\%). Ainda neste estudo, as únicas diferenças de sexo apuradas situaram-se ao nível da coerção sexual, onde os rapazes assumiram maioritariamente a perpetração desta forma de abuso (45.8\%).

A experienciação ou a exposição à violência no seio familiar, mediante maus-tratos diretos ou indiretos (vitimação vicariante), tem sido um dos fatores de risco mais consistentemente apontados pela literatura para a ocorrência de violência íntima (Dahlberg, 1998; O’Keefe, 1998). Assim, o abuso íntimo tem sido recorrentemente associado à experienciação precoce de violência em contexto familiar, sobretudo à severidade da disciplina parental (e.g., Jouriles, Mueller, Rosenfield, McDonald, \& Dodson, 2012), à experienciação de maus-tratos parentais (e.g., Wolfe, Wekerle, Scott, Straatman, \& Grasley, 2004), ou mesmo à exposição ao conflito interparental (e.g., Kaura \& Allen, 2003; O’Keefe, 1998; Tschann et al., 2009). Tem sido defendido, deste modo, que as crianças inseridas em contextos familiares abusivos, não dispõem de um processo de socialização que possibilite a promoção de competências de relacionamento interpes- 
soal e de resolução de conflitos fundamentais ao desenvolvimento de relacionamentos saudáveis (cf. Laporte, Jiang, Pepler, \& Chamberland, 2011), pelo que a exposição ao conflito familiar poderá comprometer significativamente as relações amorosas dos jovens.

A investigação em torno da tese da intergeracionalidade da violência tem, contudo, vindo a revelar resultados mistos e, por vezes, contraditórios. Assim, há evidência que comprova que a exposição a uma disciplina interparental severa poderá assumir diferentes associações com a vitimação e a perpetração da violência íntima (Laporte et al., 2011); existem fatores de risco (e.g., exposição ao conflito interparental; experienciação de maus-tratos parentais) que surgem associados à vitimação e à perpetração do abuso íntimo (cf. Gover, Kaukinen, \& Fox, 2008), assim como há fatores de risco específicos da vitimação (e.g., esperança na alteração de comportamento) e da perpetração (e.g., atitudes legitimadoras da violência) (cf. Jouriles et al., 2012); há também estudos (e.g., Stets \& Pirog-Good, 1987) que não encontraram qualquer relação estatisticamente significativa entre observar violência interparental e abuso íntimo ou mesmo entre a experienciação de maus-tratos diretos na família de origem e a violência íntima. De notar ainda, a existência de algumas divergências em matéria de sexo neste âmbito, não existindo, por exemplo, total consenso acerca da relação entre exposição à violência familiar e a ocorrência de abuso íntimo em raparigas e/ ou rapazes (cf. Gover et al., 2008; Jouriles et al., 2012). Assim, se há estudos (e.g., Foo \& Margolin, 1998; O’Keefe, 1997) que apontam para a existência de uma forte associação entre observar violência interparental e agressão e vitimação íntima masculina, outros há (e.g., Riggs \& O’Leary, 1996) que apenas encontraram esta relação no caso das raparigas, identificando-se ainda outros trabalhos (e.g., Simons, Lin, \& Gordon, 1998) que não revelaram qualquer relação (direta ou indireta) entre a exposição ao conflito interparental e a perpetração do abuso íntimo em rapazes.

Laporte e colaboradores (2011) procuraram investigar a relação entre a experienciação de violência na família e no contexto amoroso, a partir de uma amostra de adolescentes (com idades entre os 12 e 19 anos de idade) considerados de risco e adolescentes sem qualquer tipo de sinalização, tendo concluído que a influência das experiências precoces de exposição à violência familiar por parte dos adolescentes nas suas relações amorosas varia consoante o sexo e o grau de risco presente em cada caso. De forma mais específica, os autores comprovaram que: i) não existem diferenças de sexo no que respeita à associação entre os relatos de vitimação parental dos adolescentes e vitimação na intimidade; ii) os rapazes de elevado risco que admitiram sofrer violência parental na infância apresentam um risco alto para a agressão na relação amorosa, sendo esta particularmente agravada nos casos em que se verifica também exposição à disciplina severa por parte do progenitor; iii) as raparigas que foram expostas à disciplina parental severa por ambos os progenitores mostraram-se mais propensas a usar violência para com o parceiro amoroso. 
Ao contrário daquilo que se verifica no contexto internacional, onde se regista uma multiplicação de estudos que procuram analisar a relação entre abuso íntimo e exposição precoce à violência ocorrida em contexto familiar, em território nacional o investimento científico neste âmbito é ínfimo. Não obstante, é possível encontrar alguns estudos neste domínio, designadamente os trabalhos desenvolvidos por Oliveira $(2009,2014)$ no âmbito da intergeracionalidade da violência. Num estudo conduzido por Oliveira, Sani e Magalhães (2012), que envolveu uma amostra de 283 estudantes do ensino secundário, $36.6 \%$ dos participantes envolvidos em relações amorosas admitiram ter adotado pelo menos um comportamento agressivo e cerca de 57\% revelou ter sofrido abuso íntimo; $16.3 \%$ dos participantes referiram ter assistido a violência no contexto familiar, encontrando-se igualmente uma correlação positiva entre exposição à violência em contexto familiar e abuso íntimo, quer em termos de agressão quer de vitimação. Num outro trabalho, com uma amostra maior, de 1467 participantes, com idades compreendidas entre os 15 e os 20 anos de idade, Oliveira (2014) encontrou igualmente uma associação estatisticamente significativa entre a vitimação e perpetração do abuso íntimo e a experienciação de violência no contexto familiar.

Atendendo à comprovada intergeracionalidade da violência e à necessidade de romper com a mesma, o presente estudo teve como principal objetivo caracterizar a prevalência do abuso íntimo e das experiências abusivas testemunhadas em contexto familiar, procurando perceber de que forma estes dois tipos de abuso se relacionam. De forma mais específica, pretendeu-se: i) caracterizar a prevalência do abuso íntimo ocorrido nas relações íntimas juvenis, em termos de vitimação e agressão; ii) analisar a existência de diferenças de sexo ao nível do abuso íntimo iii) caracterizar o tipo de experiências abusivas testemunhadas no contexto familiar; iv) analisar a existência de diferenças de sexo ao nível da experienciação de violência familiar; v) analisar a existência de algum tipo de relação entre o abuso perpetrado e/ou sofrido no namoro e os maus-tratos experienciados na família.

Espera-se assim que a experienciação e/ou perpetração do abuso íntimo se encontre associado positivamente à exposição à violência em contexto familiar.

\section{MÉTODo}

\section{Participantes}

Integraram este estudo, um total de 505 participantes, sendo $80.6 \%$ do sexo feminino e $19.4 \%$ do sexo masculino, com uma média de idades de $21.76(D P=2.15)$ 
Relativamente às habilitações literárias dos participantes, a maioria dos respondentes referiu possuir uma licenciatura (47.3\%), seguido do $12^{\circ}$ ano (38.6\%), o mestrado $(10.7 \%)$ e com percentagens menores surgiu o bacharelato (2.2\%) e a escolaridade entre o $4^{\circ}-9^{\circ}$ ano $(1.2 \%)$. No que respeita à área de residência, a maioria da amostra relatou residir num meio urbano (78\%) e apenas uma pequena percentagem referiu residir em meios rurais (22\%). No que concerne à situação relacional, a maioria da amostra (73.1\%) afirmou possuir, no momento do preenchimento do protocolo de instrumentos, uma relação amorosa sendo que apenas uma pequena parte (26.9\%) não se encontrava atualmente inserida numa relação amorosa mas já tinha estado no passado. A média do tempo de duração da relação amorosa era de 34 meses com um desvio padrão de 50.56. O envolvimento numa relação amorosa, atual ou passado, constituiu de resto um dos critérios de inclusão na amostra.

\section{Instrumentos}

Os instrumentos utilizados neste estudo foram selecionados tendo em conta a problemática a estudar, isto é, para que permitissem explorar a relação entre a violência nos relacionamentos amorosos e a vitimação/exposição à violência familiar.

Para avaliar a violência nas relações íntimas juvenis recorremos à Escala de Táticas do Conflito Revisada (CTS-2-R), a qual foi adaptada e validada para a população portuguesa por Paiva e Figueiredo (2006).

O CTS-2-R permite caracterizar as relações amorosas e perceber de que forma os casais vivenciam as mesmas, bem como se solucionam os seus conflitos através de estratégias de resolução ou através do uso da violência, mais concretamente: a) abuso físico sem sequelas, b) agressão psicológica, c) abuso físico com sequelas, ou d) coerção sexual.

Trata-se de um instrumento constituído por 39 itens agrupados, perfazendo um total de 78 questões com um breve formato, permitindo conhecer o número de ocorrências durante o último ano. Como opções de resposta apresenta oito categorias, sendo que as seis primeiras permitem determinar a cronicidade e a prevalência no último ano: 1) uma vez no ano anterior; 2) duas vezes no ano anterior; 3) 3-5 vezes no ano anterior; 4) 6-10 vezes no ano anterior; 5) 11-20 vezes no ano anterior; 6) mais de 20 vezes no ano anterior; e as restantes destinam-se a determinar a prevalência global: 7) não no ano anterior, mas já aconteceu anteriormente; 8) isso nunca aconteceu.

Os valores apurados de consistência interna total (alpha de Cronbach) para a versão portuguesa do CTS-2-R foram os seguintes: .79 para a agressão e .80 para a vitimação. De forma mais específica ao nível da perpetração, a agressão psicológica 
apresentou um alpha de .68, o abuso físico sem sequelas de .78, a coerção sexual de .56 , o abuso físico com sequelas de .50 . Relativamente à vitimação psicológica registou-se um alpha de .64, na vitimação física sem sequelas de .74, na coerção sexual de .51 e na vitimação física com sequelas foi de .47 (Paiva \& Figueiredo, 2006). No presente estudo também se obteve uma boa consistência interna total (alpha de Cronbach), nomeadamente de .93. Nesta investigação, obtivemos na dimensão agressão psicológica um valor de .68; na dimensão negociação .43; na dimensão abuso físico sem sequelas um valor de .83; na dimensão coerção sexual .59; e por fim, na dimensão abuso físico com sequelas um valor de .86 .

Para caraterizar o meio familiar, partindo do ponto de vista do participante, de forma a identificar a existência de situações de vitimação e/ou exposição à violência recorremos à escala de Sinalização do Ambiente Natural Infantil (S.A.N.I.), construída e validada por Sani em 2003.

Esta escala é composta por 30 itens que relatam diversas situações de violência física (fator 1), emocional (fator 2), coerção (fator 3) e controlo (fator 4), apresentando dois formatos de resposta tipo likert [0 = nunca (nenhuma vez); 1 = poucas vezes (ou 2 vezes nesse ano); 2 = às vezes (mais de 2 ou 3 vezes nesse ano); 3 = muitas vezes (cerca de 1 vez por mês) e 4 = quase sempre (mais de uma vez por mês)]; e em formato de checklist remetendo para a identificação do alvo de violência. $\mathrm{Na}$ construção e validação da escala, registou-se uma consistência interna total (alpha de Cronbach) de .92. Em relação à consistência entre fatores obtiveram-se valores entre .73 e .86. No presente estudo registou-se também uma boa consistência interna total (alpha de Cronbach), sendo esta de .93 e entre fatores obtiveram-se os seguintes valores: fator 1 de .87 , fator 2 de .87 , fator 3 de .75 e o fator 4 de .71 .

\section{RESULTADOS}

\section{Prevalência do abuso íntimo e sexo}

Um dos objetivos desta investigação era caraterizar a prevalência do abuso íntimo dos participantes, em termos de perpetração e vitimação. Neste objetivo optámos apenas por analisar os participantes que se encontravam, no momento da recolha de dados, envolvidos numa relação amorosa e assim, no conjunto dos participantes incluídos neste estudo $(\mathrm{N}=505)$ somente fizeram parte desta análise estatística 369 sujeitos. 
Analisando as diferentes tipologias de violência íntima, extraídas através do CTS-2-R, e no que diz respeito à perpetração de violência, verificámos que a maioria dos participantes assumiu ter perpetrado violência psicológica (52.3\%) nas suas relações de namoro. De seguida, surgiu a coerção sexual (28.5\%) e a agressão física sem sequelas (22\%), como sendo as tipologias de violência mais reportadas pelos participantes nas suas relações amorosas. Por fim, a tipologia menos admitida pelos respondentes, foi a violência física com sequelas (3.8\%).

Esta diferenciação é igualmente manifesta ao nível da vitimação, onde a violência psicológica surgiu também como sendo a mais admitida (50.4\%) pelos participantes. Em segundo lugar, admitiram sofrer com alguma frequência coerção sexual (33.6\%) e também vitimação de violência física sem sequelas (21.4\%) com $\mathrm{o} / \mathrm{a}$ seu/sua parceiro/a. O tipo de violência menos admitido e frequente perante os participantes foi a violência física com sequelas (3\%).

Um segundo objetivo a cumprir era o de verificar qual a relação entre a prevalência do abuso íntimo e o sexo dos participantes (cf. Tabela 1).

No que respeita à perpetração de violência, a tipologia que assumiu maior preponderância relativamente aos outros tipos de abuso, foi a violência psicológica, tendo sido assumida por $75 \%$ dos participantes de sexo masculino e $71.8 \%$ de sexo feminino, não se registando, no entanto, diferenças estatisticamente significativas $\left(\chi^{2}=0.194, p=.660\right)$.

Já em relação à tipologia da coerção sexual, foi admitida maioritariamente por $46 \%$ dos rapazes e $26.7 \%$ das raparigas, tendo-se registado diferenças estatisticamente significativas $\left(\chi^{2}=9.183, p=.002\right)$. No abuso físico sem sequelas, $26.3 \%$ das raparigas assumiram um maior recurso a esta prática, comparativamente com o sexo oposto (17\%), mas não foram detetadas diferenças estatisticamente significativas $\left(\chi^{2}=2.279\right.$, $p=.131)$. A agressão física com sequelas surgiu como a menos prevalente entre os participantes, isto é, apenas $4.4 \%$ dos respondentes de sexo feminino assumiu o recurso a esse tipo de violência, comparativamente com $1.6 \%$ dos rapazes, não se verificando contudo diferenças estatisticamente significativas $\left(\chi^{2}=1.143, p=.285\right)$.

O mesmo tipo de análise foi realizado em relação ao padrão de vitimação de violência, não tendo sido encontradas quaisquer diferenças estatísticas entre o sexo dos participantes e o tipo de abuso íntimo medido. Concretamente, o abuso de violência psicológica surgiu como a tipologia mais reportada, assumido por $74 \%$ dos rapazes e $66 \%$ das raparigas, não havendo diferenças estatisticamente significativas $\left(\chi^{2}=1.068, p=.301\right)$. Por outro lado, a coerção sexual foi também admitida por $40.3 \%$ dos rapazes e $35.9 \%$ das raparigas, não existindo de igual forma diferenças estatisticamente significativas $\left(\chi^{2}=0.432, p=.511\right)$. No que diz respeito ao abuso físico sem sequelas, embora um pouco menos prevalente, foi sinalizado por $23.6 \%$ do sexo feminino e por $22 \%$ do sexo masculino, não se constatando diferenças estatis- 
ticamente significativas $\left(\chi^{2}=0.064, p=.800\right)$. Por fim, a tipologia menos reportada foi a violência física com sequelas, onde verificámos que $3.4 \%$ dos participantes de sexo feminino apontou ser vítima deste tipo de violência comparativamente com $1.5 \%$ de rapazes. Também não foram encontradas diferenças estatisticamente significativas $\left(\chi^{2}=0.653, p=.419\right)$.

Tabela 1

Associação entre o Abuso Íntimo e o Sexo dos Participantes

\begin{tabular}{lllll}
\hline \multirow{4}{*}{ Perpetração } & \multicolumn{2}{l}{ Sexo } & \multirow{2}{*}{$\chi^{2}$} \\
\cline { 3 - 4 } & Peminino (\%) & Masculino (\%) & \\
\hline \multirow{5}{*}{ Vitimaçãológica } & 71.8 & 75 & 0.194 \\
& Física sem sequelas & 26.3 & 17 & 2.279 \\
& Física com sequelas & 4.4 & 1.6 & 1.143 \\
& Coerção sexual & 26.7 & 46 & 9.183 * \\
& Psicológica & 66 & 74 & 1.068 \\
& Física sem sequelas & 23.6 & 22 & 0.064 \\
& Física com sequelas & 3.4 & 1.5 & 0.653 \\
& Coerção sexual & 35.9 & 40.3 & 0.432 \\
\hline
\end{tabular}

${ }^{*} \mathrm{p}<.01$

Caracterização dos abusos experienciados em contexto familiar

O nosso terceiro objetivo centrava-se em caracterizar as experiências abusivas, diretas ou indiretas, ocorridas no contexto familiar. De modo geral, apurámos que a maioria $(80.8 \%)$ da nossa amostra já testemunhou ou foi vítima de algum tipo de violência no contexto familiar.

O tipo de violência mais admitido e presente no contexto familiar dos participantes foi a violência emocional (74.3\%), seguido do controlo (65.9\%), a coerção (34.5\%) e, por fim, a violência física (16.4\%). Mediante a correlação de Pearson, verificámos que não existe uma correlação estatisticamente significativa entre nenhuma das tipologias de exposição à violência familiar e o sexo dos participantes (violência física: $\chi^{2}=0.022$, $p=.617$; violência emocional: $\chi^{2}=-0.053, p=.231$; coerção: $\chi^{2}=-0.044, p=.323$; controlo: $\left.\chi^{2}=-0.005, p=.916\right)$ e o score total do instrumento: $\chi^{2}=-0.037, p=.408$ ).

\section{Relação entre o abuso íntimo e a experienciação de violência no contexto familiar}

O principal objetivo desta investigação era o de perceber qual a relação que existe entre a violência nas relações de namoro e a exposição/vitimação à violência familiar (cf. Tabela 2). 
Assim, no que respeita à perpetração de violência, verificamos que a agressão psicológica se encontra estatisticamente relacionada, quer com o fator 2 (abuso emocional), quer com o fator 4 (controlo) e ainda com a totalidade do instrumento S.A.N.I. $\left(\chi^{2}=0.157, p=.010 ; \chi^{2}=0.127, p=.039 ; \chi^{2}=0.129, p=.036\right.$, respetivamente $)$.

Por sua vez, o abuso físico sem sequelas revela uma associação estatisticamente significativa com o fator 2 (abuso emocional), o fator 3 (coerção), o fator 4 (controlo) e ainda com a totalidade do instrumento S.A.N.I. $\left(\chi^{2}=0.172, p=.002 ; \chi^{2}=0.185\right.$, $\mathrm{p}=.001 ; \chi^{2}=0.200, p=.000 ; \chi^{2}=0.182, p=.001$, respetivamente) .

Já no que respeita à coerção sexual, não se verifica a existência de qualquer relação estatisticamente significativa entre este tipo de abuso e os fatores do S.A.N.I. (fator $1: \chi^{2}=-0.026, p=.630$; fator $2: \chi^{2}=0.008, p=.879$; (fator 3: $\chi^{2}=0.022, p=.687$; fator 4: $\left.\chi^{2}=0.097, p=.071\right)$ ou mesmo no que respeita ao score total do $\left(\chi^{2}=0.029, p=\right.$ .593). O mesmo se verifica em relação ao abuso físico com sequelas, seja em relação aos fatores do S.A.N.I. (fator $1: \chi^{2}=0.036, p=0.499$; fator $2: \chi^{2}=0.031, p=.566$; fator 3: $\chi^{2}=0.018, p=.737$; fator $4: \chi^{2}=0.061, p=.252$ ), seja em relação ao total do instrumento $\left(\chi^{2}=0.044, p=.407\right)$. Ao nível do padrão vitimação, e em relação ao abuso físico sem sequelas verificámos que existe uma associação estatisticamente significativa com o fator 2 (abuso emocional), com o fator 3 (coerção), com o fator 4 (controlo) e ainda com a totalidade do instrumento S.A.N.I. $\left(\chi^{2}=0.145, p=.008\right.$; $\chi^{2}=0.156, p=.004 ; \chi^{2}=0.203, p=.000 ; \chi^{2}=0.163, p=.003$, respetivamente).

Também a vitimação por coerção sexual, surge associada estatisticamente com os fatores 3 (coerção) e 4 (controlo) $\left(\chi^{2}=0.125, p=.022 ; \chi^{2}=0.124, p=.023\right.$, respetivamente). Por sua vez, o abuso físico com sequelas possui uma relação estatisticamente significativa com os fatores 1 (abuso físico) e 4 (controlo) $\left(\chi^{2}=0.110\right.$, $p=.038 ; \chi^{2}=0.105, p=.048$, respetivamente).

Por fim, a vitimação psicológica não revela qualquer associação estatisticamente significativa com os fatores do S.A.N.I. (fator $1: \chi^{2}=-0.026, p=.665$; fator 2 : $\chi^{2}=$ 0.108, $p=.075$; fator $3: \chi^{2}=0.095, p=.116$; fator $\left.4: \chi^{2}=0.110, p=.069\right)$ e o score total do instrumento $\left(\chi^{2}=0.094, p=.121\right)$ (cf. Tabela 2$)$. 
Tabela 2

Associação ( $\chi^{2}$ ) entre o Abuso Íntimo e a Exposição/Vitimação no Contexto Familiar

\begin{tabular}{|c|c|c|c|c|c|c|c|c|}
\hline & \multicolumn{4}{|c|}{ Vitimação } & \multicolumn{4}{|c|}{ Perpetração } \\
\hline & $\begin{array}{l}\text { Física } \\
\text { sem } \\
\text { sequelas }\end{array}$ & $\begin{array}{l}\text { Física } \\
\text { com } \\
\text { sequelas }\end{array}$ & $\begin{array}{l}\text { Abuso } \\
\text { psicológico }\end{array}$ & $\begin{array}{l}\text { Coerção } \\
\text { sexual }\end{array}$ & $\begin{array}{l}\text { Física } \\
\text { sem } \\
\text { sequelas }\end{array}$ & $\begin{array}{l}\text { Físico } \\
\text { com } \\
\text { sequelas }\end{array}$ & $\begin{array}{l}\text { Agressão } \\
\text { psicológica }\end{array}$ & $\begin{array}{l}\text { Coerção } \\
\text { sexual }\end{array}$ \\
\hline $\begin{array}{l}\text { Violência } \\
\text { física }\end{array}$ & 0.013 & $0.110^{*}$ & -0.026 & -0.052 & -0.001 & 0.036 & -0.055 & -0.026 \\
\hline $\begin{array}{l}\text { Violência } \\
\text { emocional }\end{array}$ & $0.145^{\star *}$ & 0.057 & 0.108 & 0.062 & $0.172^{\star *}$ & 0.031 & $0.157^{\star *}$ & 0.008 \\
\hline Coerção & $0.156^{* *}$ & 0.092 & 0.095 & $0.125^{\star}$ & $0.185^{\star * *}$ & 0.018 & 0.102 & 0.022 \\
\hline Controlo & $0.203^{* * *}$ & $0.105^{*}$ & 0.110 & $0.124^{*}$ & $0.200^{* * *}$ & 0.061 & $0.127^{\star}$ & 0.097 \\
\hline Total SANI & $0.163^{\star *}$ & 0.099 & 0.094 & 0.082 & $0.182^{* * *}$ & 0.044 & $0.129^{*}$ & 0.029 \\
\hline
\end{tabular}

\section{DISCUSSÃO DOS RESULTADOS}

A presente investigação procurou caracterizar o abuso íntimo e a experienciação da violência no contexto familiar, procurando perceber a relação existente entre estas duas formas de violência. Assim, neste estudo foi possível verificar que a maioria das relações amorosas dos nossos participantes é pautada por elevados níveis de violência psicológica, tanto em termos de perpetração (52.3\%) como de vitimação (50.4\%). Estes dados vão ao encontro das evidências apontadas pela literatura internacional (e.g., Black, Sussman, \& Unger, 2010; Gover et al., 2008; Gover, Park, Tomsich, \& Jennings, 2011) e a literatura nacional (e.g., Barros, 2014; Caridade, 2011; Guerreiro et al., 2013; Oliveira, 2009; Oliveira, 2014). Segue-se a vitimação através da coerção sexual, admitida por $33.6 \%$ dos participantes e a perpetração registada em $28.5 \%$ dos casos. Estes resultados são também em tudo similares ao apurado em outras investigações que usaram o mesmo instrumento (e.g., Carr \& Vandeusen, 2002; Paiva \& Figueiredo, 2004; Wolfe, Scott, Wekerle, \& Pittman, 2001), e onde efetivamente a violência psicológica e a coerção sexual surgem como as formas de violência mais preponderantes na intimidade dos jovens. 
Não obstante, a violência física foi igualmente reportada pelos participantes, sendo que $22 \%$ referiram já ter usado este tipo de abuso para com o/a parceiro/a amoroso/a e $21.4 \%$ admitiu ter sido alvo deste tipo de violência. Por fim, e de forma menos expressiva, mas ainda assim preocupante, surgiu a perpetração da violência física com sequelas, admitida por 3.8\% dos participantes, tendo $3 \%$ referido já ter sofrido este tipo de abuso.

No que respeita à relação entre a perpetração e a vitimação do abuso íntimo e o sexo dos participantes apenas apuramos diferenças de sexo, estatisticamente significativas, ao nível da perpetração da coerção sexual, com os rapazes a admitirem recorrer mais frequentemente a este tipo de abuso, comparativamente com as raparigas ( $26.7 \%$ vs. $46 \%$ respetivamente). Este dado está em linha com o que tem sido apurado pela maioria dos estudos neste âmbito e que usou a mesma medida de avaliação (CTS-2-R) (e.g., Carr \& Vandeusen, 2002; Paiva \& Figueiredo, 2004).

Para as restantes tipologias de violência, quer em termos de vitimação, quer de perpetração, não foram detetadas diferenças de sexo estatisticamente significativas, sugerindo a existência de alguma paridade de sexo, que de resto tem sido também documentada por outras investigações neste âmbito (e.g., Follette \& Alexander, 1992; Machado, Caridade, \& Martins, 2010; Straus, 2004). Estes dados parecem ainda apoiar a tese sustentada por Johnson (1995), que advoga que no âmbito das relações de intimidade, poderão existir diversas formas de violência, umas mais simétricas do que outras.

Um outro dado deveras relevante no presente estudo, remete para o facto de a maioria dos participantes (80.8\%) reconhecerem estar inseridos num ambiente familiar pautado por violência (direta ou indireta). De facto, os participantes identificaram a ocorrência de várias tipologias de violência no seu contexto familiar, que incluem: a violência emocional (e.g., ameaçar que vai magoar seriamente alguém, dizer coisas que envergonhem muito uma pessoa, dizer que destrói ou destruir mesmo qualquer coisa de valor), o controlo (e.g., não deixar conversar com certas pessoas, estar sempre a controlar tudo, ter ciúmes ou desconfiar muito de alguém), a coerção (e.g., pôr uma pessoa fora de casa, ameaçar com separações de pessoas da família) e a violência física (e.g., atirar com coisas contra uma pessoa de propósito, dar pontapés ou murros numa pessoa). Estes dados são consistentes com as evidências apuradas por outros estudos internacionais (e.g., Kim, Kim, \& Choi, 2014; Kingsfogel \& Grych, 2004) e nacionais (e.g., Oliveira, 2009; 2014), que comprovam que muitos jovens estão inseridos em ambientes familiares abusivos, constituindo esta evidência um forte preditor para o envolvimento em relações amorosas abusivas (Carr \& Vandeusen, 2002; Gover et al., 2008; Gover et al., 2011; Kingsfogel \& Grych, 2004; O’Keefe, 1998; Oliveira, 2009; Oliveira, 2014; Wolfe et al., 2004). A título exemplificativo, um estudo recente (Kim et al., 2014) apurou que $41 \%$ da amostra já tinha sido alvo de violência familiar e $44 \%$ admitiu ter sido exposto a esta mesma forma de violência. 
Um outro objetivo deste estudo passou por procurar perceber a relação entre a exposição e /ou vitimação a comportamentos abusivos no ambiente familiar e a ocorrência de violência na relação amorosa. Assim, na nossa amostra, concluímos que os indivíduos que tinham experienciado ou testemunhado atos de abuso emocional, controlo e coerção no contexto familiar, admitiram ter usado violência nas suas relações amorosas, designadamente a violência psicológica e o abuso físico sem sequelas. Os participantes que referiram ter sido expostos e/ou testemunharem violência no contexto familiar (abuso emocional, coerção, controlo e abuso físico), reconheceram ter sofrido abuso físico sem sequelas, coerção sexual e o abuso físico com sequelas, no âmbito das suas relações amorosas. Os nossos dados são consensuais com as evidências ao nível internacional (e.g., Black et al., 2010; Carr \& Vandeusen, 2002; Gover et al., 2008; Gover et al., 2011; Kim et al., 2014; Kingsfogel \& Grych, 2004; Laporte et al., 2011; MakinByrd \& Bierman, 2013; O’Keefe, 1998; Wolfe et al., 2004) e nacional (Doroteia, 2013; Oliveira, 2009; Oliveira, 2014), que defendem que os indivíduos que estão expostos ou testemunhem violência familiar tendem a replicar esses mesmos comportamentos nas suas relações. Tais dados atestam assim as implicações nefastas que um ambiente familiar disruptivo pode ter no desenvolvimento das relações amorosas dos jovens.

Para Wolf e Foshee (2003), este tipo de resultados poderá dever-se ao facto de os jovens que experienciam violência familiar tenderem a desenvolver estilos de expressão da raiva, tornando-se mais propensos à perpetração de comportamentos violentos nas suas relações amorosas. Ainda que esta associação se verifique em ambos os sexos, os autores concluíram pela sua maior robustez no sexo masculino (Wolf \& Foshee, 2003). A teoria da aprendizagem social, com recurso ao conceito da transmissão intergeracional de violência, tem sido um modelo explicativo recorrentemente utilizado na análise desta relação entre a vitimação na família de origem e violência na intimidade juvenil (cf. Caridade, 2011). Esta abordagem documenta que o comportamento de cada indivíduo resulta em grande medida do ambiente em que este se insere, particularmente no que respeita aos elementos da sua família, mediante mecanismos de observação, reforço, modelagem ou coação (Foo \& Margolin, 1995). Neste sentido, uma criança que tenha sido exposta à violência interparental ou que tenha sofrido maus-tratos na infância, tem mais probabilidades de reproduzir estes comportamentos e/ou de evidenciar uma maior tolerância face a estes. Tem sido defendido que a vitimação direta ou indireta (exposição ao conflito interparental) poderá contribuir para a aceitação deste tipo de práticas e, deste modo, a violência ser interpretada como uma forma adequada de resolução dos conflitos (Gómez, 2011; Riggs \& O’Leary, 1996). Foshee, Bauman, e Linder (1999) consideram, por sua vez, que o recurso à violência pelos jovens expostos ao conflito familiar poderá ser explicado pelo facto de estes associarem à violência interpessoal mais funcionalidades positivas do que consequências negativas e, consequentemente, desenvolverem expectativas positivas face ao comportamento violento. 


\section{CONCLUSÃO}

Ao procurar estudar a relação entre a experienciação de violência nas relações amorosas e a violência vivenciada no contexto familiar, o presente estudo pretendeu contribuir para o aumento do conhecimento nesta matéria. Assim sendo, e tomando em consideração as evidências científicas internacionais que documentam a intergeracionalidade da violência, a delineação deste tipo de estudos no contexto português constitui uma necessidade premente, de forma a poder extrair conhecimentos úteis para a prática preventiva destes fenómenos.

Os resultados do presente estudo sugerem que deve existir uma preocupação e necessidade acrescidas em abordar este tema, atendendo ao importante papel que o ambiente familiar parece desempenhar no desenvolvimento das dinâmicas amorosas. Urge, pois, uma atenção redobrada sobre este assunto, procurando-se a sinalização precoce deste tipo de casos, bem como a implementação de medidas, quer de prevenção quer de intervenção, que possam romper definitivamente com este ciclo de violência que a literatura da especialidade tem vindo a demonstrar.

O presente estudo apresenta, contudo, algumas limitações sobre as quais importa refletir. Desde logo, identificamos o facto de se tratar de um estudo exploratório, não permitindo pois generalizar os nossos resultados para a restante população portuguesa. A forma selecionada para a recolha da amostra - online - apesar das diversas vantagens (e.g., rápida e célere recolha, acesso a uma maior diversidade de população, custos reduzidos), apresenta também algumas desvantagens (e.g., difícil motivação de possíveis participantes, aquando de alguma dúvida ser difícil um esclarecimento). Além disso, o recurso a medidas de autorrelato tem, igualmente inerentes, algumas fragilidades, visto ser suscetível à desejabilidade social, que poderá influenciar as respostas e consequentemente nos resultados obtidos. Acresce ainda o desfasamento da amostra em termos de sexo, o que poderá ter interferido de alguma forma com os nossos resultados. E, por último, o facto de não terem sido efetuadas outras análises estatísticas mais complexas (análises de regressão), que eventualmente possibilitariam uma maior compreensão da relação entre experienciar violência no namoro e violência no contexto familiar.

Face a estas limitações, torna-se pois importante que se continue a apostar no desenvolvimento de estudos neste âmbito. Reconhecemos que seria pertinente a realização de estudos longitudinais, que ajudassem a compreender melhor a intergeracionalidade da violência.

Por fim, como implicações para a prática preventiva, defende-se que a necessidade de se continuar a apostar na prevenção precoce deste fenómeno, envolvendo não só os jovens, mas outros agentes educativos (pais, professores, pares), promovendo junto 
de todos uma mensagem de intolerância a qualquer forma de violência, seja em que contexto for (casa, escola, relações).

\section{REFERÊNCIAS}

Barros, S. (2014). Violência nas relações de namoro juvenis e ideação e comportamentos suicidas (Dissertação de mestrado não publicada). Universidade do Porto, Porto.

Black, D., Sussman, S., \& Unger, J. (2010). A further look at the intergenerational transmission of violence: Witnessing interparental violence in emerging adulthood. Journal of Interpersonal Violence, 25(6), 1022-1042. doi: 10.1177/0886260509340539

Caridade, S. (2011). Vivências íntimas violentas. Uma abordagem científica. Braga: Editora Almedina.

Carr, J., \& Vandeusen, K. (2002). The relationship between family of origin violence and dating violence in college men. Journal of Interpersonal Violence, 17(6), 630-646. doi: 10.1177/0886260502017006003

Castañeda, M., Grande, A., Diéz-Gañan, L., Sonego, M., \& Gavín, M. (2014). Violencia de pareja en jóvenes de 15 a 16 años de la comunidad de Madrid. Revista Española de Salud Pública, 88(5), 639-652.

Cuevas, C., Sabina, C., \& Bell, K. (2014). Dating violence and interpersonal victimization among a national sample of Latino youth. Journal of Adolescent Health, 55(4), 564-570. doi: 10.1016/j. jadohealth.2014.04.007

Dahlberg, L. L. (1998). Youth violence in the United States: Major trends, risk factors, and prevention approaches. American Journal of Preventive Medicine, 14, 259-272. doi: 10.1016/S07493797(98)00009-9

Doroteia, J. (2013). Violência no namoro: Atitudes legitimadoras e exposição ao conflito interparental (Dissertação de mestrado não publicada). Instituto Superior de Ciências da Saúde Egas Moniz, Caparica.

Ehlert, C. M. (2007). Adolescent dating violence: A review of literature on development, prevalence, perceptions, help seeking and prevention programs (Master's thesis, University of Wisconsin). Consultado em https://minds.wisconsin.edu/handle/1793/42279?show=full

Fernandéz-González, L., O’Leary, K., \& Muñoz-Rivas, M. (2014). Age-related changes in dating aggression in Spanish high school students. Journal of Interpersonal Violence, 29(6), 1132-1152. doi: $10.1177 / 0886260513506057$

Ferreira, M. (2011). A violência no namoro: Estudo exploratório de caracterização das reacções dos adolescentes face à violência (Dissertação de mestrado não publicada). Universidade do Minho, Braga.

Follette, V., \& Alexander, P. (1992). Dating violence: Current and historical correlates. Behavioral Assessment, 14, 39-52.

Foo, L., \& Margolin, G. (1995). A multivariate investigation of dating aggression. Journal Family Violence, 10(4), 351-377. doi: 10.1007/BF02110711

Foshee, V. A., Bauman, K. E., \& Linder, G. F. (1999). Family violence and the perpetration of adolescent dating violence: Examining social learning and social control processes. Journal of Marriage and the Family, 61(2), 331-342. doi: 10.2307/353752 
Furman, W., \& Wehner, E. (1997). Adolescent romantic relationships: A development perspective. New Directions for Child Development, 78, 21-36. doi: 10.1002/cd.23219977804

Gómez, A. (2011). Testing the cycle of violence hypothesis: Child abuse and adolescent dating violence as predictors of intimate partner violence in young adulthood. Youth \& Society, 43(1), 171-192. doi: 10.1177/0044118X09358313

Gover, A., Kaukinen, C., \& Fox, K. (2008). The relationship between violence in the family of origin and dating violence among college students. Journal of Interpersonal Violence, 23(12), 16671693. doi: $10.1177 / 0886260508314330$

Gover, A., Park, M., Tomsich, E., \& Jennings, W. (2011). Dating violence perpetration and victimization among South Korean college students: A focus on gender and childhood maltreatment. Journal of Interpersonal Violence, 26(6), 1232-1263. doi: 10.1177/0886260510368161

Guerreiro, A., Pontedeira, C., Sousa, R., Magalhães, M., Oliveira, E., \& Ribeiro, P. (2013). Intimidade e violência no namoro: Refletir a problemática nos/as jovens. Debates, 10, 14-26. Consultado em https://repositorio-aberto.up.pt/bitstream/10216/78885/2/115603.pdf

Johnson, M. P. (1995). Patriarchal terrorism and common couple violence: Two forms of violence against women. Journal of Marriage and the Family, 57(2), 283-295.

Jouriles, E. N., Mueller, V., Rosenfield, D., McDonald, R., \& Dodson, M. (2012). Teens' experiences of harsh parenting and exposure to severe intimate partner violence: Adding insult to injury in predicting teen dating violence. Psychology of Violence, 2(2), 125-138. doi: 10.1037/a0027264

Kaura, S. A., \& Allen, C. M. (2004). Dissatisfaction with relationship power and dating violence perpetration by men and women. Journal of Interpersonal Violence, 19(5), 576-588. doi:10.1177/0886260504262966

Kim, J., Kim, H., \& Choi, J. (2014). Family violence and dating violence in Korea. Journal of Family Violence, 29(1), 23-33. doi: 10.1007/s10896-013-9556-3

Kinsfogel, K., \& Grych, J. H. (2004). Interparental conflict and adolescent dating relationships: Integrating cognitive, emotional, and peer influences. Journal of Family Psychology, 18, 505-515. doi: 10.1037/0893-3200.18.3.505

Laporte, L., Jiang, D., Pepler, D., \& Chamberland, C. (2011). The relationship between adolescents experience of family violence and dating violence. Youth \& Society, 43(1), 3-27. doi: 10.1177/0044118X09336631

Machado, C., Caridade, S., \& Martins, C. (2010). Violence in juvenile dating relationship self-reported prevalence and attitudes in Portuguese sample. Journal of Family Violence, 25(1), 43-52. doi: 10.1007/s10896-009-9268-x

Makin-Byrd, K., \& Bierman, K. (2013). Individual and family predictors of the perpetration of dating violence and victimization in late adolescence. Journal of Youth and Adolescence, 42(4), 536-550. doi: 10.1007/s10964-012-9810-7

Mendes, F. (2006). Percursos da violência: Da família de origem à conjugalidade - Um estudo com jovens adultos a frequentarem o ensino superior (Dissertação de mestrado não publicada). Universidade do Porto, Porto.

O'Keefe, M. (1997). Predictors of dating violence among high school students. Journal of Interpersonal Violence, 12(4), 546-568. doi: 10.1177/088626097012004005

O'Keefe, M. (1998). Factors mediating the link between witnessing interparental violence and dating violence. Journal of Family Violence, 13(1), 39-57. doi:10.1023/A:1022860700118

Oliveira, M. (2009). Violência intergeracional: Da violência na família à violência no namoro (Dissertação de mestrado não publicada). Universidade do Porto, Porto. 
Oliveira, M. (2014). Transmissão intergeracional da violência: O contexto familiar, as relaçães de intimidade e as crenças dos jovens (Tese de doutoramento não publicada). Universidade Fernando Pessoa, Porto.

Oliveira, M. S., \& Sani, A. I. (2005). Comportamentos dos jovens universitários face à violência nas relações amorosas. In B. D. Silva \& L. S. Almeida (Coords.), Actas do VIII Congresso Galaico-Português de Psicopedagogia (pp. 1061-1074). Braga: Centro de Investigação em Educação (CIEd).

Oliveira, M. S., Sani, A. I., \& Magalhães, T. (2012). O contágio transgeracional da violência: A propósito da violência no namoro. Revista Portuguesa do Dano Corporal, 23, 175-188 doi: 10.14195/1647-8630_23_9

Paiva, C., \& Figueiredo, B. (2004). Abuso no relacionamento íntimo: Estudo de prevalência em jovens adultos portugueses. Psychologica, 36, 75-107.

Paiva, C., \& Figueiredo, B. (2006). Versão portuguesa das "Escalas de Táticas de Conflito Revisadas": Estudo de validação. Psicologia: Teoria e Prática, 8(2), 14-39. Consultado em http://pepsic. bvsalud.org/pdf/ptp/v8n2/v8n2a02.pdf

Riggs, D. S., \& O'Leary, K. D. (1996). Aggression between heterosexual dating partners: An examination of a causal model of courtship aggression. Journal of Interpersonal Violence, 11(4), 519-540. doi: $10.1177 / 088626096011004005$

Simons, R. L., Lin, K-H., \& Gordon, L. C. (1998). Socialization in the family of origin and male dating violence: A prospective study. Journal of Marriage and the Family, 60(2), 467-478. doi: $10.2307 / 353862$

Stets, J. E., \& Pirog-Good, M. A. (1989). Patterns of physical and sexual abuse for men and women in dating relationships: A descriptive analysis. Journal of Family Violence, 4(1), 63-76. doi:10.1007/ BF00985657

Straus, M. (2004). Prevalence of violence against dating partners by male and female university students worldwide. Violence Against Women, 10(7), 790-811. doi: 10.1177/1077801204265552

Tschann, J., Pasch, L., Flores, E., Marin, B., Baisch, M., \& Wibbelsman, C. (2009). Nonviolent aspects of interparental conflict and dating violence among adolescents. Journal of Family Issues, 30(3), 295-319. doi: 10.1177/0192513X08325010

Wolf, K. A., \& Foshee, V. A. (2003). Family violence, anger expression styles, and adolescent dating violence. Journal of Family Violence, 18, 309-316. doi: 10.1023/A:1026237914406

Wolfe, D., Scott, K., Wekerle, C., \& Pittman, A. (2001). Child maltreatment: Risk of adjustment problems and dating violence in adolescence. Journal of the American Academy of Child \& Adolescent Psychiatry, 40(3), 282-289. doi: 10.1097/00004583-200103000-00007

Wolfe, D., Wekerle, C., Scott, K., Straatman, A., \& Grasley, C. (2004). Predicting abuse in adolescent dating relationships over 1 year: The role of child maltreatment and trauma. Journal of Abnormal Psychology, 113(3), 406-415. doi: 10.1037/0021-843X.113.3.40 